\title{
Inseminação em ovelhas por videolaparoscopia por meio de acesso único: relato de caso
}

[Videolaparoscopic insemination in sheeps: case report]

\author{
J.R. Silva-Meirelles ${ }^{1}$, M.L. Castro ${ }^{1}$, T.G. Bergstein ${ }^{1}$, M.V. Ferrari ${ }^{2}$, P.T. Dornbusch ${ }^{2}$ \\ ${ }^{1}$ Aluna de pós-graduação - Universidade Federal do Paraná - UFPR - Curitiba, PR \\ ${ }^{2}$ Universidade Federal do Paraná - UFPR - Curitiba, PR
}

\begin{abstract}
RESUMO
A inseminação artificial (IA) proporciona melhoramento genético, intensifica o manejo animal e possibilita a utilização de sêmen de reprodutores que se encontram em diferentes regiões do país, bem como de animais de alto valor zootécnico que já morreram ou de machos que possuem subfertilidade. Por peculiaridades anatômicas das ovelhas, a inseminação artificial intrauterina transcervical é dificultosa. Dessa forma, bons resultados na IA são alcançados quando há deposição do sêmen diretamente dentro do útero, realizada por meio de laparoscopia. Atualmente, diversas técnicas laparoscópicas são utilizadas para inseminação; os métodos rotineiramente empregados são realizados através de dois ou três portais de acesso. O presente trabalho tem o objetivo de verificar a viabilidade de uma nova técnica de inseminação videolaparoscópica intrauterina em ovelhas, com o uso de um acesso único, visando a um procedimento mais eficaz, mais rápido, com menor trauma tecidual e com menor contaminação bacteriana, a fim de minimizar o desconforto pós-operatório. A média do tempo cirúrgico foi de 5,92 minutos. Não foram encontradas dificuldades para realização dos procedimentos, e os animais recuperaram-se sem nenhuma complicação. A utilização de um único acesso mostrou-se eficaz, pois reduziu o tempo cirúrgico e não apresentou complicações.
\end{abstract}

Palavras-chave: inseminação videolaparoscópica, técnica, procedimento

\begin{abstract}
Artificial Insemination (AI) provides genetic gain, enhances animal management and enables the use of semen from rams that are in different regions of the country, high-value livestock animals that have died or males who have subfertility. Because of anatomical peculiarities of sheep, transcervical intrauterine insemination is troublesome, thus good results in IA are achieved when there is deposition of semen directly into the uterus, performed by laparoscopy. Currently, various techniques are used for laparoscopic insemination, those routinely employed are conducted using two or three access portals. This study aims to verify the feasibility of a new laparoscopic intrauterine insemination in sheep using a single access, aiming at a more effective and faster procedure with less tissue trauma, minimizing postoperative discomfort and lower bacterial contamination. The mean operative time was 5,92 minutes, there were no difficulties in the procedures and the animals recovered without complications. The use of a single access was effective, reducing the time of the surgery and complications weren't observed.
\end{abstract}

Keywords: laparoscopic insemination, technique, procedure

\section{INTRODUÇÃO}

A inseminação artificial (IA) está entre as biotécnicas de reprodução que proporcionam os menores custos e os melhores resultados nos

Recebido em 25 de setembro de 2016

Aceito em 10 de outubro de 2016

E-mail: jerodrigues_vet@yahoo.com.br programas de melhoramento animal, além de proporcionar melhoramento genético e intensificação do manejo (Bicudo et al., 2003). A IA pode funcionar como um acelerador no melhoramento genético, facilitando a realização de testes de progênie e diminuindo a transmissão de doenças venéreas. Possibilita também a 
utilização de sêmen de reprodutores alojados em diferentes regiões do país ou que já morreram e torna possível a utilização na reprodução de machos com subfertilidade adquirida (Oliveira, 2009).

As ovelhas possuem cérvix pequena, fibrosa, com lúmen estreito e uma série de quatro a oito anéis em forma de funil, formando uma barreira que impede a utilização em grande escala da IA intrauterina, via transcervical, por dificultar a passagem da pipeta de inseminação (Naqvi et al., 2005). Dessa forma, bons resultados na IA são alcançados quando há deposição do sêmen diretamente dentro do útero, realizada por meio de laparoscopia (Killen e Caffery, 1982). O local de deposição do sêmen é diretamente proporcional à taxa de fecundação, portanto, quando é utilizado sêmen congelado, a taxa de fecundação na IA intrauterina por laparoscopia é maior do que a taxa de fecundação da IA transcervical (Bicudo et al., 2003) e as taxas de prenhez de ovelhas inseminadas por esse método são altas (Luther, 2008).

Atualmente, são utilizadas técnicas de inseminação por laparoscopia por meio da realização de duas ou três pequenas incisões de pele para instalação da óptica e de um ou dois portais de trabalho (Feranti et al., 2013). O presente trabalho tem o objetivo de verificar a viabilidade de uma nova técnica de inseminação videolaparoscópica intrauterina em ovelhas, com o uso de um acesso único, visando a um procedimento eficaz tanto quanto os demais, porém, mais rápido, com menor contaminação bacteriana e menor trauma tecidual, minimizando o desconforto pós-operatório.

\section{CASUÍSTICA}

Foram realizadas inseminações laparoscópicas, em ambos os cornos uterinos, de 10 ovelhas, SRD, de idades variadas. As ovelhas foram sincronizadas com implante intravaginal impregnado com 60mg de acetato de medroxiprogesterona $\quad\left(\right.$ Progespon $^{\circledR}$, Zoetis, Estados Unidos) pelo período de 12 dias. No dia da retirada do implante, foram administrados 500UI de eCG (Novormon $^{\circledR}$, Zoetis, Estados Unidos). A inseminação por laparoscopia foi realizada em tempo fixo de 50 a 56 horas após a retirada do implante intravaginal. $\mathrm{O}$ sêmen utilizado foi coletado pela manhã e refrigerado a $5^{\circ} \mathrm{C}$ pelo período máximo de 10 horas. $\mathrm{O}$ meio utilizado foi o GGL (glicina gema e leite) acrescido de $5 \%$ de gema de ovo, sendo a diluição de 1:1. O volume de sêmen utilizado foi de aproximadamente 150 microlitros por corno uterino, totalizando 300 microlitros por ovelha.

A inseminação artificial (IA) foi realizada por laparoscopia, com as ovelhas contidas em macas, em decúbito dorsal, em cefalodeclive (Trendelenburg), sedadas com xilzaina $0,5 \mathrm{mg} / \mathrm{kg}$, com anestesia local na região da cicatriz umbilical, por meio da administração de 3 mililitros de cloridrato de lidocaína $2 \%$ (Xylestesin®, Cristália, Brasil). As fêmeas estavam em jejum alimentar de 24 horas e jejum hídrico de 12 horas. Foi realizada incisão de pele com cerca de um centímetro de diâmetro em cima da cicatriz umbilical. Através dessa incisão, inseriu-se um portal de 11 milímetros de diâmetro, do tipo endotip (Karl Storz®, Alemanha), que permitiu a insuflação da cavidade abdominal com dióxido de carbono, a uma pressão máxima de $12 \mathrm{mmHg}$. As laparoscopias foram realizadas com laparoscópio da marca Richard Wolf (Richard Wolf Medical Instruments Corporation $\AA$, Panoview Plus, Alemanha), com visualização direita, visão de zero grau e canal de trabalho de $5 \mathrm{~mm}$, com fonte de luz xenon de 100 watts (Karl Storz $®$, Alemanha). Após a identificação dos cornos uterinos, foi introduzido pelo canal de trabalho o aplicador de palhetas de inseminação, com uma agulha $30 \times 8 \mathrm{~mm}$, especialmente adaptada, através da qual se injetou o sêmen diretamente no lúmen do útero, em ambos os cornos uterinos. Após a inseminação, a agulha e o aplicador foram retirados, bem como o portal e a óptica, e o pneumoperitônio foi desfeito. A incisão na linha alba foi suturada com um ponto simples isolado, com fio absorvível sintético, e a pele com um ponto em padrão Sultan, com fio não absorvível sintético.

As ovelhas permaneceram confinadas em baias até o $10^{\circ}$ dia e, durante esse período, não foi realizada nenhuma medicação pós-operatória. Todas as ovelhas foram avaliadas diariamente nesse período. No $11^{\circ}$ dia, foi realizada retirada dos pontos de pele, e as ovelhas foram soltas para ficarem a campo com o restante do rebanho.

Foram considerados no estudo: o tempo de inseminação, desde a identificação do útero até a 
retirada da agulha, as dificuldades encontradas, se houve ou não sangramento uterino no ponto de inseminação e se houve complicações, como peritonite ou perfurações.

\section{RESULTADOS E DISCUSSÃO}

A média do tempo cirúrgico foi de 364 segundos $(363 \pm 156,05)$ ou de 5,92 minutos $(5,92 \pm 2,6)$. O tempo total de cada procedimento está ilustrado na Tab. 1.

Não foram encontradas dificuldades para realização dos procedimentos pelos acadêmicos de medicina veterinária.

Na incisão de pele realizada para colocação dos portais, também não houve sangramento intenso, apenas sangramento de vasos localizados na região da cicatriz umbilical. Após a retirada da agulha de inseminação, observou-se uma pequena gota de sangue, apenas no local da punção, em todos os cornos uterinos, porém nenhum caso evoluiu para um sangramento maior.

Todos os animais recuperaram-se sem nenhuma complicação.

É de extrema importância o aprimoramento da técnica de inseminação artificial laparoscópica em ovinos, visto que esta é a que oferece os melhores resultados de concepção nessa espécie (Salamon e Maxwell, 2000). Para melhor visualização uterina durante esse procedimento, a insuflação abdominal é realizada, sendo o gás carbônico utilizado em larga escala (Luther, 2008). Feranti et al. (2013) citam também o uso rotineiro do ar ambiental administrado com bomba manual nesses procedimentos, principalmente nos que são realizados a campo.

Tabela 1. Número de inseminações artificiais laparoscópicas realizadas e tempo de duração de cada procedimento cirúrgico

\begin{tabular}{ccccccccccc}
\hline Procedimento & 1 & 2 & 3 & 4 & 5 & 6 & 7 & 8 & 9 & 10 \\
\hline Tempo (segundos) & 720 & 405 & 310 & 240 & 250 & 505 & 405 & 260 & 350 & 200 \\
\hline $\begin{array}{c}\text { Tempo } \\
\text { (minutos) }\end{array}$ & 12 & 6,45 & 5,1 & 4 & 4,1 & 8,25 & 6,45 & 4,2 & 5,5 & 3,2 \\
\hline
\end{tabular}

As fêmeas foram colocadas em decúbito dorsal, com cefalodeclive, e a insuflação da cavidade ocorreu de forma rápida e sem intercorrências, no entanto Feranti et al. (2013), ao realizarem inseminação artificial laparoscópica em 80 ovelhas, encontraram dificuldades na realização de pneumoperitônio, sendo necessária mais de uma punção com agulha Veress para obter a insuflação adequada. Esses mesmos autores citam que a realização dos procedimentos durou em média 13,76 minutos $(13,76 \pm 7,88)$; Luther (2008) cita que o tempo de procedimento pode ser de cinco a 10 minutos, os quais se aproximam do tempo médio dos procedimentos deste trabalho, que foi de três a 12 minutos, tendo como média o tempo de 5,92 minutos. $\mathrm{O}$ fato de não serem encontradas dificuldades na insuflação da cavidade e na realização do procedimento pode ter contribuído para uma menor média de tempo cirúrgico neste trabalho quando comparado às outras duas literaturas citadas.

Há mais de 30 anos a inseminação por laparoscopia vem sendo utilizada em ovelhas, pois diminui os riscos de aderências e infecções, quando comparada à inseminação por laparotomia. Apesar de amplamente utilizada e divulgada, a técnica não se alterou e continua sendo realizada da mesma maneira que Killen e Caffery (1982) descreveram, sendo realizadas duas incisões ou mais, para colocação da óptica e dos instrumentos de trabalho. No presente estudo, demonstrou-se que é possível a realização da inseminação intrauterina com apenas uma incisão, sendo utilizada uma óptica com canal de trabalho. O uso de um único acesso, ou seja, single port, reduz o tempo cirúrgico, as complicações da ferida cirúrgica e permite retorno precoce às atividades.

\section{CONCLUSÕES}

A utilização de um único acesso para inseminação artificial em ovelhas mostrou-se eficaz quando comparada às demais técnicas, pois reduziu o tempo cirúrgico, foi de fácil realização e não apresentou complicações. 


\section{REFERÊNCIAS}

BICUDO, S.D.; SOUSA, D.B.; TAKADA, L. Possibilidades e limitações da inseminação com sêmen ovino refrigerado e biotécnicas associadas como estratégias de intensificação do manejo reprodutivo. Rev. Bras. Reprod. Anim., v.27, p.120-126, 2003.

FERANTI, J.P.S.; BRUN, M.V.; ZANELLA, E. et al. Viabilidade de duas novas técnicas para inseminação intrauterina laparoscópica em ovinos. Arq. Bras. Med. Vet. Zootec., v.65, p.687-693, 2013.

KILLEN， I.D.; CAFFERY， G.J. Uterine insemination of ewes with the aid of a laparoscope. Aust. Vet. J., v.59, p.95, 1982.

LUTHER, J.S. Application of laparoscopic artificial insemination techniques to the North Dakota sheep industry. Sheep Res. Rep., p.24-26, 2008.
NAQVI, S.M.K.; PANDEY, G.K.; GAUTAM, K.K. et al. Evalution of gross anatomical features of cervix of tropical sheep using cervical silicone moulds. Anim. Reprod. Sci., v.85, p.337-344, 2005.

OLIVEIRA, M.E.F. Técnicas de inseminação artificial em ovinos e caprinos. [Jaboticabal]: [s.n.], 2009. Disponível em: <http://www.milkpoint.com.br/radartecnico/ovinos-e-caprinos/tecnicas-deinseminacao-artificial-em-ovinos-e-caprinos52391n.aspx \. Acessado em: 17 dez. 2015.

SALAMON, S.; MAXWELL, W.M.C. Storage of ram semen. Anim. Reprod. Sci., v.62, p.77$111,2000$. 